\title{
CONSTRUÇÃO E AVALIAÇÃO DE UM PROTÓTIPO DE MÁQUINA COLETORA DE ANTERAS ${ }^{1}$
}

\author{
RODRIGO TONET ${ }^{2}$, MARCOS ROBSON SACHET $^{3}$, IDEMIR CITADIN $^{4}$, ALCIR JOSÉ MODOLO $^{5}$
}

RESUMO - Um protótipo de máquina coletora de anteras foi projetado e construído, e seu desempenho foi avaliado, comparando-se com o método de coleta manual, em flores rosáceas e campanuladas de pessegueiro (Prunus persica). O trabalho foi conduzido utilizando-se do delineamento experimental inteiramente ao acaso, arranjado em um esquema bifatorial ( 2 métodos de remoção x 2 formas florais), com 12 repetições de 30 balões florais. O protótipo apresentou maior velocidade de processamento, sem diminuir a qualidade do pólen, mesmo sendo armazenadas anteras com maior quantidade de filetes e descartado maior número de anteras do que o método manual.

Termos para indexação: Prunus persica, pólen, melhoramento genético, mecanização.

\section{CONSTRUCTION AND EVALUATION OF AN ANTHER COLLECTOR PROTOTYPE MACHINE}

\begin{abstract}
An anther collector prototype machine was projected and built. Its performance was evaluated by comparisons between the use of the prototype and the traditional manual method, both for showy and nonshowy peach-tree flowers (Prunus persica). The study was accomplished in August 2011 using a completely randomized experimental design, arranged in a bi-factorial scheme ( 2 collection methods $\mathrm{x} 2$ flower forms), with 12 repetitions, each consisted by 30 flowers. The prototype proved to be faster in the anther extraction time without losses in the pollen quality, even harvesting anthers with higher fillet amounts and discarding a higher quantity of anthers than the manual method.
\end{abstract}

Index terms: Prunus persica, pollen, breeding program, mechanization.

Atualmente, há uma tendência de mecanização dos processos de cultivo visando-se a reduzir custos e aumentar a competitividade do empreendimento frutícola (ROBINSON, 2011). A mecanização reduz a penosidade do trabalho e torna as operações mais eficientes e pontuais (YOUSEFI et al., 2010; DIXIT; KHAN, 2011). Em alguns processos, a mecanização pode reduzir a qualidade do produto final (DAG et al., 2008; GUTIERREZ et al., 2009), sendo possível minimizar tais perdas através de aperfeiçoamentos nos métodos, padronização operacional e técnicas auxiliares (ARFELLI et al., 2010). Porém, em outras situações, a mecanização de processos não resulta em perdas na qualidade, mas na quantidade do produto final. Como na poda mecanizada em Citrus paradisi, em que se obteve um incremento no tamanho dos frutos, com redução na produtividade (YILDIRIM et al., 2010).

Nos programas de melhoramento genético, por serem realizados em pequena escala, a mecanização não vem ocorrendo de forma significativa. Fato esse que se deve à complexidade e à singularidade das atividades relacionadas aos processos de melhoramento genético de cada espécie, o que demandaria o desenvolvimento de uma máquina específica para cada uma dessas atividades.

No caso de programas de melhoramento de Prunus persica, a obtenção de pólen é dividida em duas fases. A primeira, realizada em campo, constituise da coleta dos balões florais coletados um dia antes

\footnotetext{
'(Trabalho 202-12). Recebido em: 04-07-2012. Aceito para publicação em: 15-02-2013.

${ }^{2}$ Engenheiro Agrônomo. Estagiário Voluntário em Melhoramento de Culturas Perenes na Universidade Tecnológica Federal do Paraná (UTFPR) - Pato Branco. E-mail: rdtonet@gmail.com

${ }^{3}$ Engenheiro Agrônomo. Mestrando do Programa de Pós-Graduação em Agronomia da Universidade Tecnológica Federal do Paraná (UTFPR) - Pato Branco. E-mail: marcos.sachet@gmail.com

${ }^{4}$ Engenheiro Agrônomo, Dr. Professor do Curso de Agronomia e do Programa de Pós-Graduação em Agronomia da Universidade Tecnológica Federal do Paraná (UTFPR) - Pato Branco. Email: idemir@utfpr.edu.br

${ }^{5}$ Engenheiro Agrícola, Dr. Professor do Curso de Agronomia e do Programa de Pós-Graduação em Agronomia da Universidade Tecnológica Federal do Paraná (UTFPR) - Pato Branco. Email: alcir@utfpr.edu.br
} 
da abertura total da flor de progenitores masculinos. A segunda fase, realizada em laboratório, resume-se na remoção das anteras dos filetes, secagem das mesmas para deiscência do pólen e armazenagem sob baixas temperaturas para posterior utilização (LAYNE; BASSI, 2008). A coleta e a armazenagem de pólen concentram-se entre julho e agosto, devendo-se priorizar a coleta de todos os acessos com aspectos agronômicos desejáveis. Esse período coincide com o de outras atividades, como a poda, as hibridações e as aplicações fitossanitárias, além da menor disponibilidade de dias úteis devido à ocorrência de chuvas e geadas.

Assim como a emasculação e a polinização, a obtenção de pólen é um trabalho executado de forma manual e, dependendo da dimensão do programa de melhoramento ao qual está vinculada, demanda uma grande quantidade de mão de obra durante um tempo considerável, que poderia ser empregada em outras atividades de laboratório ou em campo.

O objetivo deste trabalho foi desenvolver e avaliar o desempenho de um protótipo de máquina coletora de anteras, comparando-se com o método manual.

O projeto foi desenvolvido com o apoio da técnica CAD (Computer Aided Design), utilizandose do software FreeCAD. A construção da máquina foi realizada no Laboratório de Fruticultura da Universidade Tecnológica Federal do Paraná (UTFPR), Câmpus Pato Branco. O protótipo designa-se à realização de 4 funções básicas: armazenar, direcionar, cortar e separar. Para tanto, os mecanismos responsáveis por tais funções foram idealizados separadamente e acoplados em uma única estrutura (Figura 1).

O mecanismo de corte é movido por um motor de 110 volts, com potência de $0,45 \mathrm{KW}$ e rotação de $1.460 \mathrm{rpm}$ (1), acoplado a um conjunto de polias, com relação de transmissão de 0,467 e uma caixa de redução de 6:1 (2), obtendo-se na roda com os pinos preensores (3) aproximadamente $113 \mathrm{rpm}$. Os pinos preensores auxiliam no corte dos balões por forçarem a passagem pelas lâminas de bisturis, disposta em série de 8 , espaçadas entre si a $4 \mathrm{~mm}$ (4).

A máquina armazena os balões florais em um reservatório (5), do qual são removidos por ação gravitacional e vibratória para um condutor com forma de "U" (6), moldado em um cano de PVC, o qual tem como objetivo direcionar os balões ao mecanismo de corte para que a cisão ocorra transversalmente às anteras. O material cortado transversalmente é depositado sobre uma peneira com malha de $2 \mathrm{~mm}$ (7), cuja função é separar os detritos mais grosseiros (pedaços do cálice e da corola), deixando passar para a peneira de malha de $0,5 \mathrm{~mm}(\mathbf{8})$ as anteras e os filetes seccionados. Como os filetes são mais finos que as anteras, é possível separá-los mantendo as anteras sobre a peneira de malha de $0,5 \mathrm{~mm}$. O mecanismo de separação é movimentado pela vibração proporcionada por um motor de 110 volts, $0,6 \mathrm{KW}$ de potência e rotação de $3.600 \mathrm{rpm}(9)$, com uma pequena massa desbalanceada. Também, a vibração é transmitida para o reservatório (5) e o condutor (6), através de uma haste que os suporta e que está fixada sobre a plataforma de vibração.

O teste para aferir o desempenho do protótipo foi realizado entre os dias 03 e 04 de agosto de 2011, no laboratório de Fruticultura da Universidade Tecnológica Federal do Paraná, Câmpus Pato Branco. O delineamento experimental utilizado foi o inteiramente ao acaso, arranjado em um esquema bifatorial (2 métodos de remoção x 2 formas florais), com 12 repetições de 30 balões florais, aproximadamente um dia antes da total antese. $\mathrm{O}$ fator de remoção de anteras foi representado pelo processo tradicional (em uma peneira de $2 \mathrm{~mm}$, em que cada balão é processado manualmente por fricção) e pela utilização do protótipo. $\mathrm{O}$ fator tipo de flor foi constituído pelas 2 principais formas morfológicas (campanulada e rosácea). Para cada tipo de flor, foram coletadas 3 repetições de 4 genótipos (campanuladas: 'Cascata 1.065', 'Cascata 1.303', 'Cascata 587' e 'Santa Áurea'; e rosácea: 'Delicioso', 'Eldorado', 'Cascata 1.055' e ‘Conserva 681').

As variáveis analisadas foram: tempo de extração das anteras, número residual de anteras, massa fresca do coletado e percentual de germinação do pólen extraído. A germinação de pólen foi realizada de acordo com o teste in vitro, recomendado para a cultura (EINHARDT et al., 2006). Os dados foram analisados pela ANOVA e, quando significativas a $P \leq 0,05$, foram submetidos ao teste de Tukey.

Observaram-se diferenças significativas no tempo de extração entre os dois métodos de remoção (Tabela 1). O protótipo foi aproximadamente três vezes mais rápido no processo de remoção de anteras de uma amostra de 30 balões florais, independentemente do tipo floral avaliado, evidenciando sua possível aplicação na maioria dos genótipos utilizados em programa de melhoramento genético de prunóideas. Houve diferenças significativas entre os tipos florais no método manual, levando-se menor tempo para os balões campanulados, que são mais facilmente estratificados por possuírem menor volume de pétalas e apresentarem as anteras expostas antes da total antese (LAYNE; BASSI, 2008). 
A massa fresca coletada, representando a massa de anteras e filetes, não diferiu entre os tipos florais, quando avaliada no método de remoção manual. O protótipo apresentou maior massa coletada quando processadas as flores rosáceas, formada por fragmentos de filetes que não foram separados da massa das anteras na peneira de $0,05 \mathrm{~mm}$, enquanto poucos filetes foram observados junto às amostras no método manual.

A massa de filetes armazenada junto com as anteras não influenciou na qualidade do pólen, já que o pólen armazenado com filetes obtido através do uso da máquina não apresentou diferenças significativas na porcentagem de germinação em relação ao método manual. Além disso, instituições que usam um método de extração manual alternativo ao da peneira, por remoção com cortes transversais nos balões, armazenam as anteras coletadas com resíduo de filetes (LAYNE; BASSI, 2008). Pode-se observar, ainda, que para as flores campanuladas não houve diferenças significativas na massa fresca coletada pela máquina em relação ao método manual, por se tratarem de estruturas mais compactas e com menores pétalas, facilitando o corte e a separação.

O número de anteras aderidas ao resíduo foi significativamente maior, utilizando-se da máquina para ambas as formas florais avaliadas. Isso ocorreu devido às imperfeições no corte da máquina e ao fato de a máquina seccionar a flor em várias partes sem levar em consideração a posição em que as anteras se situam na flor, podendo permanecer anteras no interior de secções da corola. O método manual foi mais eficiente por atuar diretamente, removendo as anteras que são atritadas contra a peneira. Observouse que ambas as formas florais não diferenciaram significativamente no número de anteras residuais no método de extração manual, evidenciando a eficiência deste método na remoção das anteras.

Para as campanuladas, o pólen coletado pela máquina apresentou porcentagem de germinação significativamente maior em relação aos dois fatores. A máquina atua com maior eficiência sobre as anteras com filetes mais longos e mais próximas ao ponto de abertura da flor, enquanto os balões campanulados têm como característica o atrofiamento de alguns filetes, fazendo com que as anteras fiquem voltadas para dentro da corola, dificultando o corte e a separação, como observado. O número de anteras no resíduo era predominantemente de anteras aderidas aos filetes menores e atrofiados. Assim, possivelmente, as anteras mais desenvolvidas e maduras foram retiradas pela máquina em maior percentual que as atrofiadas, resultando em maior viabilidade do pólen coletado. Não houve diferenças significativas na germinação do pólen coletado manualmente em comparação ao coletado pela máquina para as flores de forma rosácea, resultado importante, já que se visa a que o uso da máquina não cause diminuição na qualidade do pólen.

Como o pólen recomendado para hibridações controladas não deve ter viabilidade menor que 30\% (EINHARDT et al., 2006), o pólen coletado durante as avaliações pode ser desconsiderado para este fim. A baixa germinação do pólen resultou do excesso de chuvas nos dias que precederam à coleta dos balões florais.

Em resumo, o protótipo apresentou maior eficiência em termos de velocidade de processamento, sem diminuir a qualidade do pólen, mesmo sendo armazenadas anteras com presença de filetes. Recomenda-se seu uso para armazenamento de pólen de amostras grandes e em ocasiões que vários genótipos de interesse estejam na mesma fase fenológica e necessitam, concomitantemente, de recolhimento de pólen e hibridações. O método manual apresentou coletado com menos impureza e menos perda de anteras; com isso, recomenda-se para amostras com poucos balões de genótipos raros e de grande interesse.

Há a possibilidade de ajustar ou adaptar o protótipo para outras culturas, desde que apresentem flores actinomorfas sob as quais as funções básicas da máquina possam ser efetuadas. Também, é necessário que essas flores não apresentem alta umidade ou alta produção de néctar, como as flores de mirtilo.

Para uma versão comercial, sugere-se a construção da máquina em aço inoxidável, protegendo-se as partes móveis a fim de evitar acidentes (BRASIL, 1994). Os conjuntos de lâminas e pinos preensores podem ser acoplados a um sistema de engate rápido, facilitando as operações de higienização, manutenção, regulagem e substituição. A esterilização para que não ocorra mistura de pólen de materiais distintos pode ser realizada com auxílio de ar comprimido e álcool (70\%). 


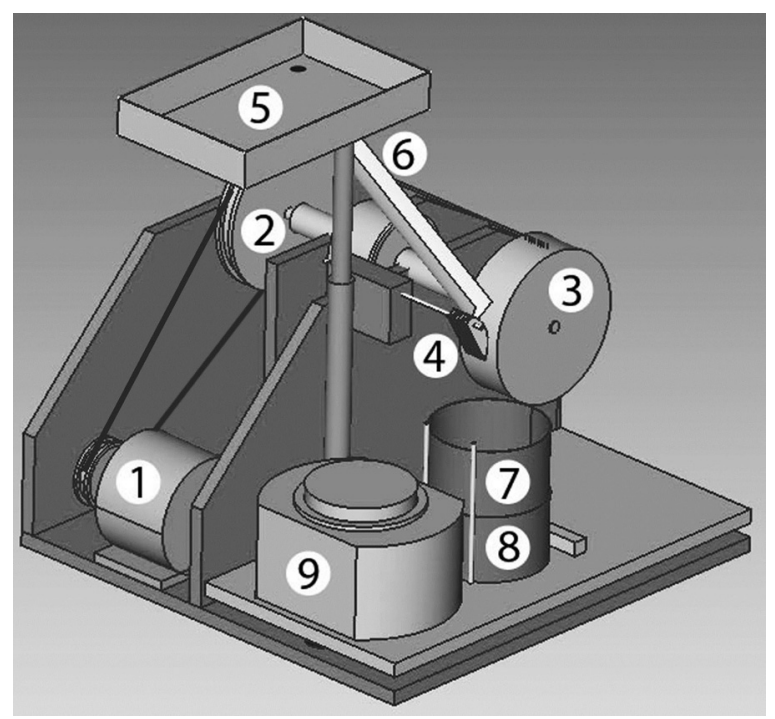

\begin{tabular}{|c|c|}
\hline Código & Descrição \\
\hline 1 & Motor 110 V, 1.460 RPM e 0,45 KW \\
\hline 2 & Caixa de redução 6:1 \\
\hline 3 & Roda com pinos auxiliares ao corte \\
\hline 4 & Série de 8 lâminas para corte \\
\hline 5 & Reservatório de balões florais \\
\hline 6 & Condutor de balões \\
\hline 7 & Peneira de 2 mm \\
\hline 8 & Peneira de 0,5 mm \\
\hline 9 & Motor com mecanismo de vibração \\
\hline
\end{tabular}

FIGURA 1- Perspectiva do protótipo de máquina coletora de anteras e seus principais componentes. UTFPR, Câmpus Pato Branco, 2012.

TABELA 1- Valores comparativos para tempo de remoção das anteras, massa fresca coletada, número de anteras no resíduo e germinação do pólen em 30 balões florais de pessegueiros do tipo rosácea e campanulada, processados manualmente ou pelo protótipo de máquina removedora de anteras. UTFPR, Câmpus Pato Branco, 2012.

\begin{tabular}{|c|c|c|c|}
\hline Tipo floral & Manual & Máquina & Média \\
\hline & \multicolumn{3}{|c|}{ Tempo de remoção (segundos) } \\
\hline Rosácea & $170,3 \mathrm{Aa}$ & $54,0 \mathrm{Ab}$ & 112 \\
\hline Campanulada & $159,6 \mathrm{Ba}$ & $50,4 \mathrm{Ab}$ & 105 \\
\hline Média & 165,0 & 52,2 & \\
\hline \multicolumn{4}{|l|}{$\mathrm{CV}=9,2 \%$} \\
\hline & \multicolumn{3}{|c|}{ Massa fresca coletada (g) } \\
\hline Rosácea & $0,278 \mathrm{Ab}$ & $0,408 \mathrm{Aa}$ & 0,34 \\
\hline Campanulada & $0,261 \mathrm{Aa}$ & $0,292 \mathrm{Ba}$ & 0,27 \\
\hline Média & 0,27 & 0,35 & \\
\hline \multicolumn{4}{|l|}{$\mathrm{CV}=28,6 \%$} \\
\hline & \multicolumn{3}{|c|}{ Número de anteras no resíduo } \\
\hline Rosácea & $96^{\mathrm{ns}}$ & 356 & 226 \\
\hline Campanulada & 105 & 409 & 257 \\
\hline Média & $100,5 \mathrm{~b}$ & $382,5 \mathrm{a}$ & \\
\hline \multicolumn{4}{|l|}{$\mathrm{CV}=35 \%$} \\
\hline & \multicolumn{3}{|c|}{ Germinação do pólen (\%) } \\
\hline Rosácea & $23,4 \mathrm{Aa}$ & $20,7 \mathrm{Ba}$ & 22 \\
\hline Campanulada & $21,5 \mathrm{Ab}$ & $26,6 \mathrm{Aa}$ & 24,1 \\
\hline Média & 22,4 & 23,6 & \\
\hline $\mathrm{CV}=23 \%$ & & & \\
\hline
\end{tabular}

Médias seguidas de letras distintas, maiúsculas na coluna, e minúsculas na linha, diferem significativamente, pelo teste de Tukey $(P \leq 0,05)$. ${ }^{n s}$ Interação não significativa a $P \leq 0,05$ pelo teste $\mathrm{F}$. 


\section{REFERÊNCIAS}

ARFELLI, G.; SARTINI, E.; BORDINI, F.; CAPRARA, C.; PEZZI, F. Mechanical Harvesting Optimization and Postharvest Treatments to Improve Wine Quality. Journal International des Sciences de la Vigne et du Vin, Mosciano Sant Angelo, v.44, n.2, p. 101-115, 2010.

BRASIL. Decreto n. 1255 , de 29 de setembro de 1994. Promulga a Convenção n. 119 da Organização Internacional do Trabalho sobre Proteção das Máquinas, em Genebra, em 25 de junho de 1963. Lex: coletânea de legislação e Jurisprudência: legislação federal e marginalia, São Paulo, v.58, p.1271-1277, 1994.

DAG, A.; BEN-GAL, A.; YERMIYAHU, U.; BASHEER, L.; NIR, Y.; KEREM, Z. The Effect of Irrigation Level and Harvest Mechanization on Virgin Olive Oil Quality in a Traditional Rain-fed 'Souri' Olive Orchard Converted to Irrigation, Journal of the Science of Food and Agriculture, Revohot, v.88, n.9, p. 1524-1528, 2008.

DIXIT, J; KHAN, J.N. Comparative Field Evaluation of Self-Propelled Paddy Transplanter with Hand Transplanting in Valley Lands of Kashmir Region. AMA-Agricultural Mechanization in Asia, Africa and Latin America, Tokyo, v.42, n.2, p. 14-18, 2011.

EINHARDT, P. M.; CORREA, E. R.; RASEIRA, M. do C. B. Comparação entre métodos para testar a viabilidade de pólen de pessegueiro. Revista Brasileira de Fruticultura, Jaboticabal, v.28, n.1, p. 5-7, 2006.
GUTIERREZ, C.; SERWATOWSKI, R.; GRACIA, C.; CABRERA, J. M.; SALDANA, N. Design, building and testing of a transplanting mechanism for strawberry plants of bare root on mulched soil. Spanish Journal of Agricultural Research, Madrid, v.7, n.4, p. 791-799, 2009.

LAYNE, D.R; BASSI, D. The Peach: botany, production and uses. Wallingford: CAB International, 2008. 615 p.

ROBINSON, T. Advances in apple culture worldwide. Revista Brasileira de Fruticultura, Jaboticabal, vol.33, p. 37-47, 2011. Número especial

YILDIRIM, B.; YEŞILOĞLU, T.; İNCESU, M.; KAMILOĞLU, M.; ÖZGÜVEN, F.; TUZCU, O.; KAÇAR Y. The Effects of Mechanical Pruning on Fruit Yield and Quality in 'Star Ruby' Grapefruit. Journal of Food Agriculture \& Environment, Helsinki, v.8 n.2, p. 834-838, 2010.

YOUSEFI, Z.; ALMASSI, M.; ZEINANLOO, A. A.; MOGHADASI, R.; KHORSHIDI, M. B. A Comparative Study of Olive Removal Techniques and Their Effects on Harvest Productivity. Journal of Food Agriculture \& Environment, Helsinki, v.8, n.1, p. 240-243, 2010. 